\title{
Vitamin D: too much testing and treating?
}

\author{
Authors: Henry ] Woodford, ${ }^{A}$ Scott Barrett ${ }^{B}$ and Stewart Pattman ${ }^{C}$
}

There is clinical uncertainty as to the testing of serum 25-Hydroxy vitamin D (25[OH]D) concentrations and when to use high-dose supplementation. Data show that there has been a rapid increase in the number of tests performed within the Northumbria Healthcare NHS Foundation Trust over the past 8 years and an increase in high-dose supplementation over the past 5 years. We performed a retrospective analysis of the 25(OH)D test requests over the period from January to October 2017. A total of 17,405 tests were performed in this time period. The overall average concentration was $57.5 \mathrm{nmol} / \mathrm{L}$ and this figure was similar across age groups, although a larger proportion of patients aged over $75 \mathrm{had}$ a concentration $<25 \mathrm{nmol} / \mathrm{L}$. Test requests were classified into 'appropriate', 'inappropriate' and 'uncertain' categories based on current expert opinion. We found that between $70.4 \%$ and $77.5 \%$ of tests could be inappropriate, depending on whether the 'uncertain' categories of falls and osteoporosis are considered to be justified. Tiredness, fatigue or exhaustion was the reason for testing in $22.4 \%$ of requests. We suggest that a more rational approach to testing, and subsequent treating, could lead to reductions in costs to the healthcare system and patients.

KEYWORDS: Vitamin D, colecalciferol, testing, treatment

\section{Introduction}

The appropriate testing of serum concentrations of 25-Hydroxy vitamin $\mathrm{D}(25[\mathrm{OH}] \mathrm{D})$ and supplementation when found to be low are controversial topics. Observational studies have linked lower $25(\mathrm{OH}) \mathrm{D}$ concentration with a range of adverse health outcomes. This has led to speculation that correcting low values could have a range of health benefits, although of course, the association might have no causal relationship. For example, people who are in a poorer good state of health might go outdoors less often and so get less sunlight exposure and generate less $25(\mathrm{OH})$ D. In addition, serum $25(\mathrm{OH}) \mathrm{D}$ concentrations are believed to have a negative acute phase response; that is, they dip during periods of inflammation. Randomised controlled trials of $25(\mathrm{OH})$

Authors: ${ }^{\text {A }}$ consultant geriatrician, North Tyneside General Hospital, Northumbria Healthcare NHS Foundation Trust, North Shields, UK; ${ }^{B}$ pharmacist, North Tyneside General Hospital, Northumbria Healthcare NHS Foundation Trust, North Shields, UK; ${ }^{C}$ consultant chemical pathologist, North Tyneside General Hospital Northumbria Healthcare NHS Foundation Trust, North Shields, UK
D supplementation provide more reliable data than those from observational studies. However, decades of trials comparing $25(\mathrm{OH}) \mathrm{D}$ supplementation, at various doses and formulations, to placebo have failed to demonstrate an overall benefit in a range of conditions, ${ }^{1}$ including both falls and fractures in older people. ${ }^{2,3}$ However, the proportion of people with very low concentrations of $25(\mathrm{OH}) \mathrm{D}$ recruited to studies to date has been inconsistent. A meta-analysis of trials assessing non-skeletal effects found that a mean baseline $25(\mathrm{OH}) \mathrm{D}$ concentration $<50 \mathrm{nmol} / \mathrm{L}$ was present in fewer than half of the studies, ${ }^{4}$ which raises the possibility that a genuine beneficial effect for the most deficient patients has been missed. Recent analyses suggested that supplementation reduces the risk of acute respiratory tract infections and asthma exacerbations. ${ }^{5,6}$ These data raise the question as to when, if ever, testing 25(OH)D concentration would be clinically useful.

In addition, as a consequence of finding a low $25(\mathrm{OH}) \mathrm{D}$, clinicians might prescribe a course of high-dose supplementation to more rapidly normalise the value. However, there is a risk that higher doses of 25(OH)D can have harmful effects. For example, in a study of older women, very high doses of $25(\mathrm{OH})$ D supplementation (colecalciferol 500,000 international units [IU]) given annually resulted in higher rates of falls and fractures compared with placebo. ${ }^{7}$ It could also be contributing to the burden of polypharmacy for some patients.

Therefore, when is it clinically appropriate to measure $25(\mathrm{OH})$ $\mathrm{D}$ concentration and what action should be taken in response to detecting a low value? With respect to bone health, The National Osteoporosis Society (NOS) has produced a guideline with recommendations on when to test and when to offer treatment with high-dose supplementation. ${ }^{8}$ Their guidance favours $25(\mathrm{OH}) \mathrm{D}$ testing for patients with clinical features suggestive of osteomalacia (Box 1) or for those patients about to start treatment with a potent antiresorptive agent (ie zoledronate or denosumab). The testing of $25(\mathrm{OH}) \mathrm{D}$ in patients with suspected

Box 1. Recognised clinical features of osteomalacia
Generalised bone or muscle pain
$>$ Proximal myopathy
Hypocalcaemia
Hypophosphataemia
> Raised alkaline phosphatase
Raised parathyroid hormone
Looser zones seen on X-ray 


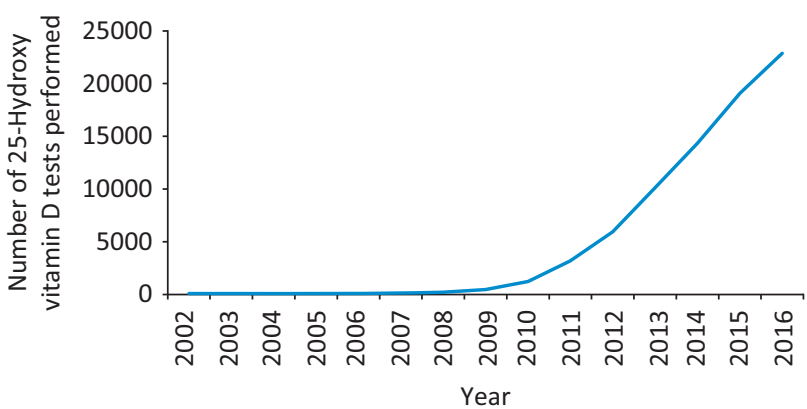

Fig 1. The number of 25-Hydroxy vitamin $D$ tests performed by the Northumbria Healthcare NHS Trust clinical chemistry laboratory from 2002 to 2016

osteoporosis is less clear cut and might be unnecessary in patients starting to take low-dose $25(\mathrm{OH}) \mathrm{D}$ supplementation (eg $800 \mathrm{IU}$ daily) as part of their treatment regardless of the result. High-dose supplementation (ie >2,000 IU daily) is recommended only for patients with symptomatic osteomalacia or those about to start a potent antiresorptive medication.

Other recognised reasons for testing $25(\mathrm{OH}) \mathrm{D}$ are patients with a suspected malabsorption state (eg inflammatory bowel disease, coeliac disease, cystic fibrosis or previous gastric bypass surgery) or patients taking medication that affect $25(\mathrm{OH}) \mathrm{D}$ metabolism (eg phenobarbital, carbamazepine, phenytoin or valproate). It is unclear from available data whether high-dose $25(\mathrm{OH}) \mathrm{D}$ supplementation would be justified when concentrations were found to be low for any of these indications. Some groups of clinicians recommend the testing of $25(\mathrm{OH}) \mathrm{D}$ concentration in many patients presenting with falls. ${ }^{9}$ However, this practice is not universally accepted and the role of $25(\mathrm{OH}) \mathrm{D}$ supplementation, at any dose, in reducing falls risk has not yet been clearly established.

The number of tests done to measure $25(\mathrm{OH}) \mathrm{D}$ concentration appears to be rapidly increasing. The number performed within the Northumbria Healthcare NHS Foundation Trust per year was low between 2002 and 2007 (<100) but rose dramatically from

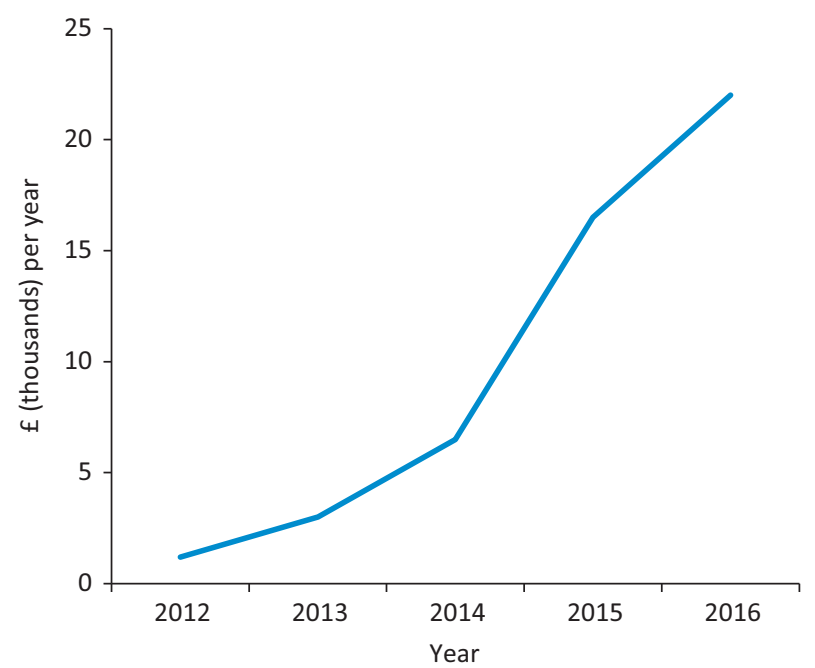

Fig 2. Spending on colecalciferol 20,000 IU within the Northumbria Healthcare NHS Trust from 2012 to 2016. IU = international units
2008 to 2016, up to 22,871 (Fig 1). This was coupled with an increase in trust spending on high-dose colecalciferol (20,000 IU) between 2012 and 2016 (Fig 2) from just over $£ 1,000$ per year to $£ 22,000$ per year. This led us to question whether current practice is clinically justified. Rational testing of $25(\mathrm{OH}) \mathrm{D}$ and, where appropriate, supplementation could reduce harm resulting from additional blood tests, polypharmacy and medication adverse effects, and also potentially reduce financial costs to the NHS. To evaluate this further, we performed a review of this testing and the prescription of high-dose colecalciferol within our trust.

\section{Methods}

A list of 25(OH)D test requests that included patient demographic details and test indications was obtained from the trust laboratory database for the time period of 1 January to 3 October 2017 (within our trust, 25[OH]D is measured on serum using a Roche immunoassay). Indications for performing the test were obtained by a search of the free text requests entered by the requester for relevant terms to enable meaningful analysis. In addition, data regarding the prescription of high-dose supplementation, which is mainly colecalciferol 20,000 IU in our trust, was obtained using Rxinfo Refine software.

Research Ethics Committee approval and consent to participate was not required for the use of fully anonymised data collected in this retrospective non-interventional process.

\section{Results}

From 1 January 2017 to 3 October 2017, 17,405 25(OH)D tests were performed. The proportion of tests of females was $70.3 \%$ and this was similar across all age groups. Nearly $40 \%$ of tests were performed on patients aged between 30 and 60 years, and approximately $25 \%$ in patients aged 60 to 75 and those 75 and over (Table 1).

Table 2 shows the breakdown of tests by indication and the indications are grouped into those of known appropriateness, those where the indication is of uncertain merit, and those where the indication does not appear clearly justified. Overall, $22.4 \%$ of tests were judged to be appropriate and this proportion was similar across age groups. Having an uncertain justification was more common in patients aged over 75 , which was explained by a larger proportion of tests done because of the patients having had a fall or suspected osteoporosis. These data suggest that between $70.4 \%$ and $77.5 \%$ of tests are inappropriate, depending on whether the 'uncertain' categories are considered to be justified.

Table 3 shows the data that were also available for calcium, phosphate and alkaline phosphatase (ALP) values when tested at the same time as $25(\mathrm{OH}) \mathrm{D}$. The data are also shown for those patients with an abnormal result who also had a $25(\mathrm{OH})$ D concentration $<25 \mathrm{nmol} / \mathrm{L}$. The overall proportion in this group who had a low serum corrected calcium $(<2.10)$ was $38.0 \%$, low serum phosphate $(<0.8)$ was $31.0 \%$ and raised $\operatorname{ALP}(>120)$ was $26.5 \%$. These figures suggest that having a very low $25(\mathrm{OH}) \mathrm{D}$ concentration is associated with a greater probability of abnormal bone biochemistry and this association is strongest for a low serum corrected calcium result. However, none of these tests would have a sensitivity or specificity suitable to aid the selection of patients for $25(\mathrm{OH}) \mathrm{D}$ testing.

\section{Discussion}

Given that it is generally accepted that $25(\mathrm{OH}) \mathrm{D}$ concentrations are lower in older age, it is perhaps surprising that the average 
Table 1. Breakdown of 25-Hydroxy vitamin D concentrations by age

\begin{tabular}{|c|c|c|c|c|c|c|}
\hline Age (years) & $\%$ of total tests & Average $\mathrm{nmol} / \mathrm{L}$ & $\%<25 \mathrm{nmol} / \mathrm{L}$ & $\%$ 25-50 nmol/L & $\%$ 50-75 nmol/L & $\%>75 \mathrm{nmol} / \mathrm{L}$ \\
\hline 75 and over & 26.4 & 56.8 & 25.9 & 24.2 & 20.2 & 29.7 \\
\hline $60-74.9$ & 25.2 & 60.8 & 15.8 & 26.0 & 27.3 & 30.9 \\
\hline $30-59.9$ & 38.5 & 57.1 & 13.4 & 32.7 & 28.5 & 25.4 \\
\hline$<30$ & 9.9 & 52.6 & 15.9 & 37.3 & 26.5 & 20.3 \\
\hline Total & 100 & 57.5 & 17.5 & 29.2 & 25.8 & 27.4 \\
\hline
\end{tabular}

$25(\mathrm{OH}) \mathrm{D}$ values were so similar across the age groups tested. ${ }^{10}$ Although a larger proportion of the over $75 \mathrm{~s}$ had concentrations $<25 \mathrm{nmol} / \mathrm{L}$, this was partially offset by a higher than average number of patients in the older age group having results $>75 \mathrm{nmol} / \mathrm{L}$. This might be explained by a greater proportion of patients who were already taking $25(\mathrm{OH}) \mathrm{D}$ supplements, because we do not have data on currently prescribed medications. In our data set, approximately half of all age groups had a value $<50 \mathrm{nmol} / \mathrm{L}$ (the level typically described as 'inadequate'). This might be influenced by the fact that our trust is situated in the northeast of England, which is likely to have lower than average sunlight exposure compared with more southern parts of the UK.

There are some shortcomings in the use of immunoassays to measure serum 25(OH)D. The NOS guidelines highlight their inability to identify all forms of vitamin D and state that high performance liquid chromatography (HPLC) or tandem mass spectrometry methods should be used for the measurement of serum vitamin $\mathrm{D}$ metabolites. These latter techniques are currently less automated and so the large number of requests means that immunoassays are still used for practical reasons in most clinical laboratories.

Our data show that a large proportion of $25(\mathrm{OH}) \mathrm{D}$ tests are done without a clearly valid clinical indication. Many were requested for vague symptoms that are not known to either be caused by low $25(\mathrm{OH}) \mathrm{D}$ concentration or improved by supplementation. In particular, tiredness (including fatigue, malaise or exhaustion) was the indication for $22.4 \%$ of tests overall and $31.3 \%$ of tests in patients aged less than 60 years. Another large group of potentially inappropriate tests we have labelled as procedural. Requests were common for indications such as 'routine', 'admitted to hospital' or 'elderly screen'. Taking all of these together, the percentage of inappropriate tests was approximately $70-80 \%$ of samples, depending on whether falls or osteoporosis are seen as appropriate indications. However, a potential weakness of this approach to analysis is the quality of the information provided on the request. Inaccurate details might have been provided by the person completing the form, who might have been doing this task

Table 2. Indications for performing 25-Hydroxy vitamin D testing across age ranges

\begin{tabular}{|c|c|c|c|c|c|}
\hline Indication $^{a}$ & All (\%) & $75+(\%)$ & $60-74.9(\%)$ & $30-59.9(\%)$ & $<30(\%)$ \\
\hline \multicolumn{6}{|l|}{ Appropriate } \\
\hline Potent antiresorptive agent ${ }^{a}$ & $176(1.0)$ & $102(2.2)$ & $58(1.3)$ & $16(0.2)$ & 0 \\
\hline Suspected osteomalacia ${ }^{b}$ & $3315(19.0)$ & $751(16.4)$ & $876(20.0)$ & $1373(20.5)$ & $315(18.3)$ \\
\hline Malabsorption $^{c}$ & $331(1.9)$ & $119(2.6)$ & $116(2.6)$ & $184(2.7)$ & $55(3.2)$ \\
\hline Epilepsy treatment $^{d}$ & $85(0.5)$ & $7(0.2)$ & $23(0.5)$ & $47(0.7)$ & $8(0.5)$ \\
\hline Total $\%$ & 22.4 & 21.3 & 24.5 & 24.2 & 22.0 \\
\hline \multicolumn{6}{|l|}{ Uncertain } \\
\hline Falls $^{\mathrm{e}}$ & $593(3.4)$ & $441(9.6)$ & $107(2.4)$ & $41(0.6)$ & $4(0.2)$ \\
\hline Osteoporosis $^{\mathrm{f}}$ & $645(3.7)$ & $506(11.0)$ & $280(6.4)$ & $242(3.6)$ & $17(1.0)$ \\
\hline Total $\%$ & 7.1 & 20.6 & 8.8 & 4.2 & 1.2 \\
\hline \multicolumn{6}{|l|}{ Inappropriate (common examples) } \\
\hline Non-specific symptoms ${ }^{g}$ & $4492(26.9)$ & $859(18.7)$ & $926(21.1)$ & $2248(33.5)$ & $652(37.9)$ \\
\hline Procedural $^{h}$ & $3308(19.0)$ & $1120(24.4)$ & $899(20.5)$ & $1048(15.6)$ & $241(14.0)$ \\
\hline Neuropsychiatric & $503(2.9)$ & $254(5.5)$ & $69(1.6)$ & $137(2.0)$ & $43(2.5)$ \\
\hline $\begin{array}{l}\text { Total (excluding appropriate and } \\
\text { uncertain indications) \% }\end{array}$ & 70.4 & 58.1 & 66.7 & 71.6 & 76.8 \\
\hline \multicolumn{6}{|c|}{ 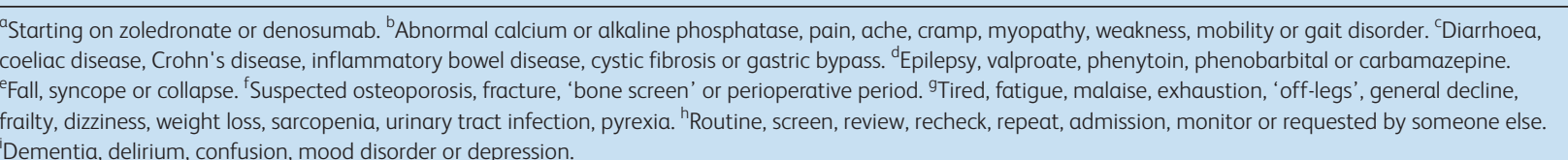 } \\
\hline
\end{tabular}


Table 3. Calcium, phosphate and alkaline phosphatase concentrations

\begin{tabular}{|c|c|c|c|}
\hline & $\begin{array}{l}\text { Age } \\
\text { group } \\
\text { (years) }\end{array}$ & $\begin{array}{l}\text { Total with } \\
\text { abnormal } \\
\text { value (\% of } \\
\text { those tested) }\end{array}$ & $\begin{array}{l}\text { Also with } \\
25(\mathrm{OH}) \mathrm{D}<25 \\
\text { (\% of those } \\
\text { with low value) }\end{array}$ \\
\hline \multirow{2}{*}{$\begin{array}{l}\text { Serum corrected } \\
\text { calcium }\end{array}$} & Total & $121(1.3)$ & $46(38.0)$ \\
\hline & $75+$ & $41(1.5)$ & $18(43.9)$ \\
\hline$n=9,465$ & $60-74.9$ & $35(1.4)$ & $13(37.1)$ \\
\hline \multirow[t]{2}{*}{ Abnormal $<2.10$} & $30-59.9$ & $44(1.3)$ & $15(34.1)$ \\
\hline & $<30$ & $1(<0.1)$ & 0 \\
\hline Phosphate & Total & $242(7.5)$ & 75 (31.0) \\
\hline$n=3,211$ & $75+$ & $102(8.9)$ & $45(44.1)$ \\
\hline \multirow[t]{3}{*}{ Abnormal $<0.8$} & $60-74.9$ & $58(6.6)$ & $13(22.4)$ \\
\hline & $30-59.9$ & $73(7.8)$ & 15 (20.5) \\
\hline & $<30$ & $9(3.6)$ & $2(22.2)$ \\
\hline Alkaline phosphatase & Total & $2656(23.3)$ & $704(26.5)$ \\
\hline$n=11,399$ & $75+$ & $938(34.1)$ & $317(33.8)$ \\
\hline \multirow[t]{3}{*}{ Abnormal $>120$} & $60-74.9$ & $802(28.5)$ & $192(23.9)$ \\
\hline & $30-59.9$ & $695(14.9)$ & $152(21.9)$ \\
\hline & $<30$ & $311(26.8)$ & $43(13.8)$ \\
\hline
\end{tabular}

for someone else and perhaps be non-medical in training. A valid indication might have been omitted. The lack of strong association between results for serum corrected calcium, serum phosphate, ALP values and having a very low $25(\mathrm{OH}) \mathrm{D}$ concentration suggests that they cannot be used to reliably identify those who should have their $25(\mathrm{OH}) \mathrm{D}$ tested.

Our trust is not alone in seeing this increase in $25(\mathrm{OH}) \mathrm{D}$ testing and the findings are mirrored in other sites nationally. ${ }^{11}$ The increase has also been observed in other healthcare systems. In Australia, the rate of requesting increased from 42 per 100,000 in the year 2000 to 3,472 per 100,000 in $2011 .{ }^{12}$ Currently, within our local population, this figure sits at 4,417 requests per 100,000 , or the equivalent of around 1 in 22 people tested each year.

Within our trust, the cost of performing a $25(\mathrm{OH}) \mathrm{D}$ test has been calculated as $£ 9.86$. Therefore, the 22,871 tests performed in 2016 cost around $£ 225,000$. If $70 \%$ of the tests were unnecessary, then a cost saving of up to $£ 158,000$ could be made by more rational testing. The population covered by our trust numbers just over half a million people. If the same savings could be realised across the UK, then the cost saving could be up to $£ 1.9$ million in testing alone. Assuming that highdose colecalciferol prescribing is being driven by inappropriate $25(\mathrm{OH}) \mathrm{D}$ requests, then reducing testing could have cost savings through fewer supplements being prescribed. In our trust alone, a $70 \%$ reduction in high-dose colecalciferol would save approximately $£ 15,000$ per year and potentially a greater sum for primary care. In addition, rationalising testing would remove the burden of blood sampling from the patient and lessen the risk of increasing polypharmacy. In any case, many of the patients tested without a clear reason for measuring 25(OH)D might have fulfilled criteria highlighted by the chief medical officer in 2012 recommending standardised replacement of vitamin D in 'at risk groups', including patients aged 65 and over not exposed to much sunlight without the need for testing. ${ }^{13}$ At a national level, an alternative option to address low $25(\mathrm{OH}) \mathrm{D}$ concentrations would be to introduce a widespread policy, such as fortification of food. Currently in the UK, a vitamin D intake of $10 \mu \mathrm{g}$ per day (400 IU/d) is recommended for people aged over 4 years. ${ }^{14}$ There are data from Finland showing that the routine fortification of foods (ie fat spreads, milk and milk-substitute liquids) can improve a population's $25(\mathrm{OH}) \mathrm{D}$ status. Over an 11-year period following implementation, the proportion of people with a $25(\mathrm{OH}) \mathrm{D}$ concentration $>50 \mathrm{nmol} / \mathrm{L}$ rose from $44 \%$ to $91 \% .{ }^{15}$ Adopting such a policy in the UK could 'demedicalise' vitamin D status and remove the need for widespread testing and supplementation and so reduce costs to the healthcare system. An alternative option could be provided by the widely available over-thecounter vitamin D supplements that avoid the need for a medical prescription.

In summary, the number of $25(\mathrm{OH}) \mathrm{D}$ tests performed has increased rapidly over the past few years, with resulting increases in prescriptions of high-dose supplements. Many of the tests do not appear to be justified clinically. This is resulting in unnecessary costs to both the healthcare system and patients.

\section{References}

1 Theodoratou E, Tzoulaki I, Zgaga L et al. Vitamin D and multiple health outcomes: umbrella review of systematic reviews and meta-analyses of observational studies and randomised trials. BMJ 2014:348:g2035.

2 Avenell A, Mak JCS, O'Connell D. Vitamin D and vitamin D analogues for preventing fractures in post-menopausal women and older men. Cochrane Database Syst Rev 2014;4:CD000227.

3 Bolland MJ, Avenell A, Grey A. Should adults take vitamin D supplements to prevent disease? BMJ 2016;355:i6201.

4 Rejnmark L, Bisle LS, Cashman KD et al. Non-skeletal health effects of vitamin $D$ supplementation: a systematic review on findings from meta-analyses summarizing trial data. PLOS ONE 2017;12:e0180512.

5 Martineau AR, Jolliffe DA, Hooper RL et al. Vitamin D supplementation to prevent acute respiratory tract infections: systematic review and meta-analysis of individual participant data. $B M J$ 2017;356:16583.

6 Jolliffe DA, Greenberg L, Hooper RL et al. Vitamin D supplementation to prevent asthma exacerbations: a systematic review and meta-analysis of individual participant data. Lancet Resp Med 2017:5:881-90.

7 Sanders KM, Stuart AL, Williamson EJ et al. Annual high-dose ora vitamin $D$ and falls and fractures in older women: a randomized controlled trial. JAMA 2010;303:1815-22.

8 National Osteoporosis Society. Vitamin D and bone health: a practical clinical guideline for patient management. London: NOS, 2013.

9 Panel on Prevention of Falls in Older Persons. Summary of the updated American Geriatrics Society/British Geriatrics Society clinical practice guideline for prevention of falls in older persons. J Am Geriatr Soc 2011:59:148-57.

10 Hirani V, Primatesta P. Vitamin D concentrations among people aged 65 years and over living in private households and institutions in England: population survey. Age Ageing 2005;34:485-91.

11 Bilinski K, Boyages S. The rise and rise of vitamin D testing. BMJ 2012;345:e4743. 
12 Zhao S, Gardner K, Taylor W et al. Vitamin D assessment in primary care: changing patterns of testing. Lond J Prim Care 2015:7:15-22.

13 Chief Medical Officers, 2012. www.gov.uk/government/uploads/ system/uploads/attachment_data/file/213703/dh_132508.pdf [Accessed 6 February 2018].

14 Scientific Advisory Committee on Nutrition. Vitamin D and Health, 2016. www.gov.uk/government/uploads/system/uploads/ attachment_data/file/537616/SACN_Vitamin_D_and_Health_ report.pdf [Accessed 6 February 2018].
15 Jaaskelainen T, Itkonen ST, Lundqvist A et al. The positive impact of general vitamin $D$ food fortification policy on vitamin $D$ status in a representative adult Finnish population: evidence from an 11-y follow-up based on standardized 25-hydroxy vitamin D data. Am J Clin Nutr 2017;105:1512-20.

Address for correspondence: Dr Henry ] Woodford, Northumbria Healthcare NHS Foundation Trust, Elderly Medicine, Rake Lane, North Shields NE29 8NH, UK. Email: henry.woodford@nhct.nhs.uk

'This landmark report lays out in the starkest terms yet the devastating impact air pollution is having on our health, our economy and our society as a whole.'

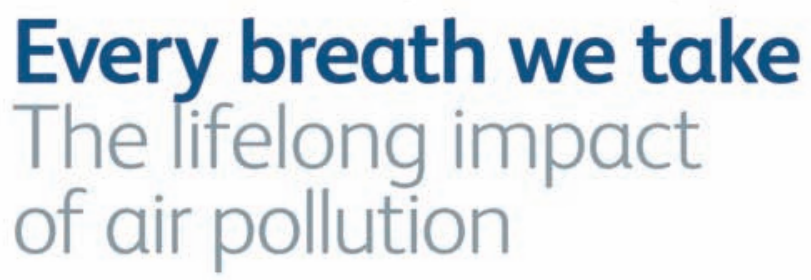

This major report plainly sets out the dangerous impact that air pollution has on our nation's health. Compiled by experts in medicine and environmental sciences, the report discusses the current evidence and draws up recommendations for action.

ISBN 978-1-86016-567-2 £15 including $p+p$ or free to download

Royal College of Physicians
Download the report: rcplondon.ac.uk/pollution

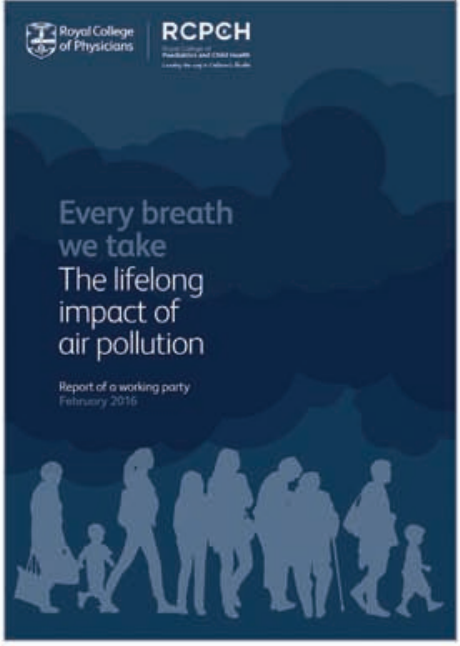

Order a copy: shop.rcplondon.ac.uk 